\title{
ANALISIS CAKUPAN PEMERIKSAAN KEHAMILAN DI WILAYAH KERJA PUSKESMAS WOLIO KOTA BAUBAU
}

\author{
Wahyuddin $^{\bowtie}$, Agus Darmawan, Ni’ma Meilani, Taswin \\ Fakultas Kesehatan Masyarakat, Universitas Dayanu Ikhsanuddin Baubau
}

\begin{tabular}{l}
\hline ARTICLE INFO \\
\hline Article history \\
Submitted : 2020-01-20 \\
Revised : 2020-01-21 \\
Accepted : 2020-08-14 \\
Keywords: \\
Pregnancy \\
Family Support \\
Distance \\
Quality of Service
\end{tabular}

\section{Kata Kunci:}

Kehamilan

Dukungan Keluarga

Jarak

Kualitas Pelayanan

\begin{abstract}
The visiting scope for pregnancy woman can be percentage with using indicator performance K1 and K4. Wolio health center have pregnancy check up scope in 2017 wes low, compane with pregnancy check up scope in 2016 was high. The purpose of this research is to know the related factor with pregnancy check up scope in working area wolio association public health of Baubau City. The kind of research that using is quantitative cross sectional approachment. With 122 population of people that do pregnancy check up in working area of wolio health center of baubau town in 2018. The sample in this research taken by total sampling method. The data collection by primer data with quisioner and do direct observation and secondary data. Tabulation of data analysis with SPSS with chi-square $(\alpha=0,05)$ test. The result of research show that there are related between quality of pregnancy check up ( $\mathrm{p}$ value $=0,002<0,05)$, distance between home and health fasilitation ( $\mathrm{p}$ value $=0,011<0,05$ ), the support of family ( $\mathrm{p}$ value $=0,005<0,05$ ) pregnancy check up scope in wolio health center of Baubau town. The conclusion of this research tell that the quality of pregnancy check up, the distance between home to health facilitation and family support have close relation ship with pregnancy check up scope. The sugestion to health center side is to be desirable that increase the approachment and cooperation with the society.
\end{abstract}

Cakupan kunjungan ibu hamil dapat dinilai dengan menggunakan indikator capaian K1 dan K4. Puskesmas Wolio memiliki cakupan pemeriksaan kehamilan yang rendah pada tahun 2017, dibandingkan dengan cakupan pemeriksaan kehamilan yang tinggi pada tahun 2016. Tujuan penelitian ini untuk mengetahui faktor yang berhubungan dengan cakupan pemeriksaan kehamilan di Wilayah Kerja Puskesmas Wolio Kota Baubau. Jenis penelitian yang digunakan adalah kuantitatif dengan pendekatan cross sectional. Dengan jumlah populasi sebanyak 122 ibu yang telah melahirkan di Wilayah Kerja Puskesmas Wolio Kota Baubau pada tahun 2018. Sampel dalam penelitian ini diambil dengan menggunakan metode Total sampling. Pengumpulan data melalui data primer yaitu dengan menggunakan kuesioner serta melakukan pengamatan secara langsung dan data sekunder. Pengolahan analisis data dengan menggunakan SPSS dengan uji ChiSquare $(\alpha=0,05)$. Hasil penelitian menunjukkan bahwa ada hubungan antara kualitas pemeriksaan kehamilan ( $\mathrm{p}$ value $=0,002<0,05$ ), Jarak rumah ke pelayanan kesehatan ( $\mathrm{p}$ value $=0,011<0,05)$, Dukungan keluarga $(\mathrm{p}$ value $=0,005<0,05)$ terhadap cakupan pemeriksaan kehamilan di Wilayah Kerja Puskesmas Wolio Kota Baubau. Kesimpulan dari penelitian ini bahwa kualitas pemeriksaan kehamilan, jarak rumah ke pelayanan kesehatan serta dukungan keluarga tersebut berhubungan erat dengan faktor cakupan pemeriksaan kehamilan. Saran Bagi pihak puskesmas harus terus meningkatkan jalinan kepercayaan, pendekatan dan kerjasama dengan masyarakat.

Corresponding Author:

\section{Wahyuddin}

Fakultas Kesehatan Masyarakat Universitas Dayanu Ikhsanuddin Baubau

Telp. 085241952936

Email: wahyu4977@gmail.com

\section{PENDAHULUAN}

Data Cakupan K1 adalah suatu penjelasan dari banyaknya ibu hamil yang melakukan kontrol atau kunjungan yang pertama ke Fasyankes (Fasilitas Pelayanan Kesehatan) dengan tujuan untuk mendapatkan layanan Kesehatan Ibu dan Anak (KIA) atau biasa disebut pula antenatal care, sedangkan data cakupan K4 merupakan penjelasan dari banyaknya ibu hamil yang sudah mendapatkan pelayanan antenatal care yang sesuai dengan standar ketentuan yang berlaku, dimana minimal kunjungan adalah empat kali dengan pembagian, 1 kali kunjungan pada trimester 
pertama, 1 kali kunjungan pada trimester dua dan 2 kali kunjungan pada trimester ketiga umur kehamilan (Kemenkes, 2016).

Data Cakupan pemeriksaan kehamilan atau antenatal care Indonesia (82\%), dimana menurut WHO 2011, saat ini masih berada dibawah jika dibandingkan negara-negara ASEAN yang lain misalnya Negara Korea Utara (95\%), Srilanka (93\%), dan Maladewa (85\%). (Dengo \& Mohamad, 2019). Menurut Badan penelitian dan pengembangan kemenkes RI, AKI tahun 2009 mencapai 226 per 100.000 kelahiran hidup (Kemenkes, 2014).

Cakupan K1 di Indonesia pada tahun 2014 telah dicatat yaitu 94,99\%, sementara cakupan K4 adalah $86,70 \%$. Untuk data cakupan K4, menunjukkan bahwa masih belum juga mencapai target Rencana Strategis (Renstra) Kementerian Kesehatan, dimana cakupan pelayanan kesehatan ibu hamil K4 yaitu sebanyak 95\% dan di Indonesia sendiri hanya ada dua provinsi yang telah mencapai target yaitu Provinsi DKI Jakarta dan Sulawesi Utara (Kemenkes, 2015).

Data yang ada pada Provinsi Sulawesi Tenggara dalam 5 tahun terakhir, yaitu cakupan K1 dan K4 dari hasil yang telah didapatkan, untuk cakupan K1 pada tahun 2011 sampai tahun 2013 terjadi penurunan data, sementara pada tahun 2013 sampai tahun 2015 telah mengalami peningkatan, begitu juga dengan cakupan K4, yang cakupan datanya hampur sama dengan cakupan K1. Data hasil tersebut tidak bermakna bahwa karena kinerja petugas di lapangan yang kurang baik, namun dikarenakan oleh system dari pencatatan yang dilakukan lebih baik dan lengkap sehingga data yang dihasilkan lebih akurat.

Berdasarkan data proyeksi wilayah kerja Puskesmas Wolio Tahun 2016, didapatkan data jumlah penduduknya 13.503 jiwa, dimana Kelurahan Wangkanapi 8.005 dan Kelurahan Batulo 5.478 jiwa, serta jumlah KK sebanyak 3.838. Pemeriksaan kehamilan yang diukur berdasarkan jumlah pemeriksaan kehamilan ibu di tempat pelayanan kesehatan. Untuk pertama (kontak pertama) disingkat K1 sedangkan yang lengkap disebut K4. Cakupan kunjungan ibu hamil di wilayah kerja Puskesmas Wolio Kota Baubau pada tahun 2016, menunjukkan data yang melakukan pemeriksaan kehamilan pada kunjungan pertama (K1) sebanyak 251 orang $(88,7 \%)$, kujungan kedua (K2) sebanyak 98 orang
(32,9\%), kunjungan ketiga (K3) sebanyak 77 orang $(25,9 \%)$ dan kunjungan keempat (K4) sebanyak 241 orang $(85,2 \%)$. Sedangkan pada tahun 2017 yang melakukan pemeriksaan kehamilan pada kunjungan pertama (K1) sebanyak 212 orang $(86,60 \%)$, kujungan kedua (K2) sebanyak 65 orang $(26,85 \%)$, kunjungan ketiga (K3) sebanyak 42 orang $(17,35 \%)$ dan kunjungan keempat (K4) sebanyak 203 orang $(83,88 \%)$. Data tersebut menyatakan bahwa telah terjadi penurunan dibanding tahun sebelumnya serta belum mencapai terget. Kondisi ini memberikan gambaran bahwa pencapaian masih di bawah target yang harus dicapai yakni K1 100\% dan K4 95\%. (Puskesmas Wolio, 2017).

Adapun tujuan dari penelitian ini yaitu untuk mengetahui faktor yang berhubungan dengan cakupan pemeriksaan kehamilan di wilayah kerja puskesmas Wolio Kota Baubau.

\section{METODE PENELITIAN \\ Jenis Penelitian}

Jenis penelitian yang digunakan adalah penelitiaan kuantitatif dengan rancangan cross sectional study.

\section{Lokasi dan Waktu Penelitian}

Penelitian ini dilakukan di wilayah kerja Pusekasmas Wolio pada Bulan Oktober Tahun 2018.

\section{Populasi dan Sampel}

Populasi dalam penelitian ini adalah seluruh ibu yang melahirkan diwilayah kerja puskesmas Wolio tahun 2018. Jumlah sampel dalam penelitian ini sebanyak 122 responden. Teknik pengambilan sampel menggunakan total sampling.

\section{Pengumpulan Data}

Jenis dan teknik pengumpulan data adalah data primer yang diperoleh dengan cara memberikan pertanyaan kepada responden yang mengacu pada kuesioner yang dibagikan berdasarkan kriteria yang telah ditetapkan dan data sekunder diperoleh dari puskesmas.

\section{Pengolahan dan Penyajian Data}

Pengolahan dan penyajian data dilakukan dengan menggunakan alat bantu komputer yaitu diawali dengan proses pemeriksaan data yang ditemukan, pemberian kode, penginputan, dan yang terakhir adalah tabulasi. 


\section{Analisis Data}

Teknik analisis data dalam penelitian ini adalah analisis univariat yang bertujuan untuk menjelaskan atau mendeskripsikan setiap variabel pada penelitian. Analisis ini, pada umunya hanya menghasilkan distribusi dan persentase dari setiap variabel.

Analisis bivariat juga dilakukan terhadap variabel independen dan variabel dependen yang diduga memiliki hubungan atau berkorelasi. Adapun uji yang dipakai adalah Chi-Square Test dengan batas tingkat kemaknaan $\alpha=0,05$.

\section{HASIL PENELITIAN}

Berdasarkan hasil pengolahan data yang telah dilakukan, maka disajikan hasil penelitian sebagai berikut :

Tabel 1. Distribusi Frekuensi Responden berdasarkan Karakteristik Umur, Pendidikan, dan Pekerjaan di Wilayah Kerja Puskesmas Wolio Kota Baubau

\begin{tabular}{lcc}
\hline $\begin{array}{c}\text { Karakteristik } \\
\text { Responden }\end{array}$ & n & \% \\
\hline Kelompok Umur (Tahun) & & \\
$16-22$ & 6 & 13,1 \\
$23-29$ & 52 & 42,6 \\
$30-36$ & 45 & 36,9 \\
$37-43$ & 9 & 7,4 \\
Pendidikan Terakhir & & \\
$\quad$ SMP/sederajat & 14 & 11,5 \\
SMA/sederajat & 68 & 55,7 \\
Akademi/Sarjana & 40 & 32,8 \\
Pekerjaan & & \\
IRT & 77 & 63,1 \\
Wiraswasta & 18 & 14,8 \\
Karyawan Swasta & 17 & 13,9 \\
PNS/TNI/POLRI & 10 & 8,2 \\
\hline Data Primer, 2018 & &
\end{tabular}

Hasil penelitian tentang karakteristik responden menunjukkan bahwa dari 122 responden, kelompok umur responden yang tertinggi yaitu kelompok umur 23 - 29 tahun sebanyak 52 responden dengan persentase $42,6 \%$ dan yang terendah adalah kelompok umur 37 - 43 tahun dengan jumlah 9 responden dengan persentase sebesar 7,4\%. Data pendidikan tertinggi yaitu SMA/sederajat sebanyak 68 responden dengan persentase
$55,7 \%$ dan yang terendah adalah SMP/sederajat sebanyak 14 responden dengan persentase sebesar 11,5\%. Berdasarkan pekerjaan menunjukkan bahwa sebagai IRT sebanyak 77 responden dengan persentase $63,1 \%$ lebih tinggi dari pada wiraswasta sebanyak 18 responden dengan persentase sebesar 14,8\%.

\section{Tabel 2. Distribusi Frekuensi Responden berdasarkan Paritas}

\begin{tabular}{ccc}
\hline Paritas & n & \% \\
\hline Anak ke 1 & 37 & 30,3 \\
Anak ke 2 & 28 & 23,0 \\
Anak ke 3 & 27 & 22,1 \\
Anak ke 4 & 17 & 13,9 \\
Anak ke 5 & 8 & 6,6 \\
Anak ke 6 & 3 & 2,5 \\
Anak ke 7 & 1 & 8 \\
Anak ke 8 & 1 & 8 \\
Anak ke 9 & 37 & 30,3 \\
\hline
\end{tabular}

Data primer, 2018

Berdasarkan data paritas, frekuensi responden terbanyak yaitu kelahiran anak ke 1 sebanyak 37 orang $(30,3 \%)$. Kemudian frekuensi responden terendah yaitu kelahiran anak ke 8 dan 9 sebanyak 1 orang $(8 \%)$.

\section{Tabel 3. Distribusi Frekuensi Responden berdasarkan Kualitas Pelayanan, Jarak Rumah, dan Dukungan Keluarga}

\begin{tabular}{|c|c|c|}
\hline Variabel Penelitian & $\mathbf{n}$ & $\%$ \\
\hline \multicolumn{3}{|c|}{ Kualitas pelayanan pemeriksaan kehamilan } \\
\hline Standar & 102 & 83,6 \\
\hline Tidak Standar & 20 & 16,4 \\
\hline \multicolumn{3}{|c|}{ Jarak rumah ke pelayanan kesehatan } \\
\hline Mudah & 105 & 86,1 \\
\hline Sulit & 17 & 13,9 \\
\hline \multicolumn{3}{|l|}{ Dukungan keluarga } \\
\hline Mendukung & 101 & 82,8 \\
\hline Tidak Mendukung & 21 & 17,2 \\
\hline
\end{tabular}

Data Primer, 2018

Berdasarkan tabel 3. menunjukkan variabel kualitas pelayanan pemeriksaan kehamilan yaitu sebanyak 102 responden dengan persentase 83,6 \%, dan tidak standar sebanyak 20 responden $(16,4 \%)$. Variabel jarak rumah ke pelayanan kesehatan mudah yaitu sebanyak 105 responden dengan persentase 
$86,1 \%$, dan sulit sebanyak 17 responden $(13,9 \%)$. Variabel dukungan keluarga, mendukung yaitu sebanyak 101 responden dengan persentase $82,8 \%$, dan tidak mendukung sebanyak 21 responden $(17,2 \%)$.

Tabel 4. Distribusi Frekuensi Responden berdasarkan Kualitas Pemeriksaan Kehamilan, Jarak Rumah, dan Dukungan Keluarga terhadap Cakupan Pemeriksaan Kehamilan

\begin{tabular}{|c|c|c|c|c|c|c|c|}
\hline \multirow{3}{*}{ Variabel } & \multicolumn{6}{|c|}{ Cakupan Pemeriksaan Kehamilan } & \multirow{3}{*}{ Uji Chi-Square } \\
\hline & \multicolumn{2}{|c|}{ Lengkap } & \multicolumn{2}{|c|}{ Tidak Lengkap } & \multicolumn{2}{|c|}{ Total } & \\
\hline & $\mathbf{n}$ & $\%$ & $\mathbf{n}$ & $\%$ & $\bar{n}$ & $\%$ & \\
\hline \multicolumn{8}{|c|}{ Kualitas Pemeriksaan Kehamilan } \\
\hline Standar & 57 & 95,0 & 45 & 72,6 & 102 & 100 & \multirow{3}{*}{$\rho=0,002$} \\
\hline Tidak Standar & 3 & 5,0 & 17 & 27,4 & 20 & 100 & \\
\hline Total & 60 & 100 & 62 & 100 & 122 & 100 & \\
\hline \multicolumn{8}{|c|}{ Jarak Rumah ke Pelayanan Kesehatan } \\
\hline Mudah & 57 & 95,0 & 48 & 77,4 & 105 & 86,1 & \multirow{3}{*}{$\rho=0,011$} \\
\hline Sulit & 3 & 5,0 & 14 & 22,6 & 17 & 13,9 & \\
\hline Total & 60 & 100 & 62 & 100 & 122 & 100 & \\
\hline \multicolumn{8}{|l|}{ Dukungan Keluarga } \\
\hline Mendukung & 56 & 93,3 & 45 & 72,6 & 102 & 100 & \multirow{3}{*}{$\rho=0,005$} \\
\hline Tidak Mendukung & 4 & 6,7 & 17 & 27,4 & 21 & 100 & \\
\hline Total & 60 & 100 & 62 & 56,9 & 122 & 100 & \\
\hline
\end{tabular}

Data Primer, 2018

Hasil analisis variabel kualitas pemeriksaan kehamilan menunjukkan bahwa dari 122 responden yang mengatakan memenuhi standar dengan hasil data cakupan kunjungan kehamilan lengkap adalah 57 responden $(95,0 \%)$, yang tidak lengkap 45 orang responden $(72,6 \%)$, sedangkan yang mengatakan tidak standar dengan cakupan pemeriksaan atau kunjungan kehamilan lengkap yaitu 3 orang responden $(5,0 \%)$ dan yang cakupan pemeriksaannya yang tidak lengkap sebanyak 17 orang responden $(27,4 \%)$. Hasil dari uji statistik dengan tingkat kepercayaan 95\% didapatkan hasil nilai $\rho=0,002<\alpha$ maka $\mathrm{H}_{0}$ ditolak dan $\mathrm{Ha}$ dapat diterima, yang berarti terdapat hubungan antara kualitas pemeriksaan kehamilan dengan cakupan pemeriksaan kehamilan di wilayah kerja puskesmas Wolio.

Jarak ke Fasilitas layanan kesehatan menunjukkan bahwa dari 122 responden yang menyatakan mudah dengan cakupan pemeriksaan kehamilan lengkap sebanyak 57 responden $(95,0 \%)$, dan tidak lengkap sebanyak 48 responden (77,4\%), sedangkan yang mengatakan sulit dengan cakupan kunjungan pemeriksaan kehamilan lengkap sebanyak 3 orang responden $(5,0 \%)$ dan tidak lengkap sebanyak 14 orang responden $(22,6 \%)$.
Berdasarkan hasil uji statistik dengan tingkat kepercayaan 95\% dengan ini nilai $\rho=0,011<\alpha$ maka dapat dinyatakan bahwa $\mathrm{H}_{0}$ ditolak dan Ha dapat diterima yang berarti ada hubungan antara jarak ke pelayanan kesehatan dengan cakupan pemeriksaan kehamilan di wilayah kerja puskesmas Wolio. Responden yang menyatakan dukungan keluarga dengan cakupan kunjungan pemeriksaan kehamilan lengkap yaitu 56 orang responden $(93,3 \%)$, dan cakupannya tidak lengkap juga adalah 45 orang responden $(72,6 \%)$, sementara yang tidak mendukung dengan cakupan kunjungan pemeriksaan kehamilan ibu yang lengkap sebanyak 4 responden $(6,7 \%)$ dan yang tidak lengkap adalah 17 orang responden $(27,4 \%)$.

Data hasil dari uji statistik dengan tingkat kepercayaan 95\% dengan ini nilai $\rho=$ $0,011<\alpha$ maka disimpulkan juga $\mathrm{H}_{0}$ ditolak dan $\mathrm{Ha}$ yang dapat diterima, atau berarti terdapat hubungan antara dukungan dari keluarga dengan cakupan pemeriksaan kehamilan di wilayah kerja Puskesmas Wolio.

\section{PEMBAHASAN}

Hubungan Kualitas Pemeriksaan Kehamilan dengan Cakupan Pemeriksaan Kehamilan 
Berdasarkan dari hasil penelitian ini menyatakan bahwa terdapat hubungan dari kualitas pemeriksaan kehamilan dengan cakupan kunjungan pemeriksaan kehamilan di Puskesmas Wolio dengan hasil dari uji Statistik dengan uji Chi-Square ( $\rho$ value $=0.002<0.05$ ) Dalam cakupan pemeriksaan kehamilan di Puskesmas Wolio, dimana hasil ini menunjukkan bahwa ibu hamil, menyatakan bahwa kualitas pemeriksaan kehamilan memiliki pengaruh yang kuat dalam cakupan pemeriksaan kehamilan di Puskesmas Wolio.

Dari data hasil ini menunjukkan bahwa, ibu yang menyatakan kualitas pelayanan kesehatan yang standar dengan cakupan pemeriksaan kehamilannya yang lengkap adalah sebanyak 57 orang. Hal ini disebabkan oleh ibu hamil yang rutin memeriksakan kehamilannya sesuai jadwal kontrol yang tentukan sehingga seluruh rangkaian proses pemeriksaan kehamilan dilakukan dengan benar dan juga lengkap mulai dari pelayanan penimbangan berat badan disertai pengukuran tinggi badan, pemeriksaan tekanan darah, pengukuran LILA (Lingkar Lengan Atas), pemberian vaksin TT atau anti tetanus, palpasi Leopold, pemeriksaan darah yang diambil dari ujung jari, pemberian tablet penambah darah serta mendapatkan pendidikan kesehatan dimuali dari pertama periksa kehamilan sampai kunjungan terakhir dekat dengan persalinan dan petugasnya juga ramah kepada setiap pasien sehingga ibu hamil yang melakukan kunjungan pemeriksaan kehamilan yang nyaman untuk melakukan pemeriksaan kehamilan ibu.

Ibu yang menyatakan bahwa kualitas pemeriksaan kehamilan sudah standar tetapi tidak lengkap cakupan pemeriksaan kehamilannya sebanyak 45 orang. Hal ini dikarenakan ibu yang tidak teratur memeriksakan kehamilannya yang hanya berkunjung di puskesmas wolio pada saat kunjungan pertama saja dan ada juga yang berkunjung pada usia kehamilan masuk trimester ke tiga sehingga cakupan pemeriksaan kehamilannya tidak lengkap.

Adapun ibu yang menyatakan kualitas pemeriksaan kehamilan tidak standar tetapi cakupan pemeriksaan kehamilannya lengkap sebanyak 3 orang hal ini disebabkan oleh ibu yang memeriksakan Imunisasi TT hanya sekali saja selama melakukan kunjungan dan ada pula yang tidak mendapatkan kesempatan untuk konseling dengan bidan tetapi karena sikap ibu yang menginginkan kondisinya serta janin yang dikandungnya dalam keadaan baik sehingga ibu tetap melakukan pemeriksaan kehamilan secara teratur sesuai jadwal yang ditetapkan oleh bidan.

Ibu yang juga menyatakan kualitas pemeriksaan tidak standar dengan cakupan pemeriksaan kehamilannya yang tidak lengkap sebanyak 17 orang hal ini dikarenakan sebagian ibu yang tidak rutin memeriksaksn kehamilannya serta kualitas pelayanan seperti USG di Puskesmas Wolio mengalami kerusakan sehingga ibu memeriksakan kehamilannya di tempat pelayanan yang menyediakan USG, dengan adanya klinik khusus ibu bersalin sehingga catatan kunjungan di puskesmas tidak lengkap serta ibu yang masih memeriksakan kehamilannya di dukun bayi dan kunjungan ANC hanya dilakukan sekali saja saat mendekati waktu persalinan.

Penelitian ini sejalan dengan hasil penelitian (Rachmawati et al., 2017) yang menunjukkan hasil bahwa faktor kualitas pemeriksaan pada kehamilan ibu masuk dalam kategori faktor penguat dalam menentukan keteraturan pada pemeriksaan antenatal care ibu hamil.

\section{Hubungan Jarak ke Pelayanan Kesehatan dengan Cakupan Pemeriksaan Kehamilan}

Hasil penelitian ini menunjukkan bahwa ada hubungan antara jarak ke pelayanan kesehatan dengan cakupan kunjungan pemeriksaan pada kehamilan di Puskesmas Wolio dengan hasil dari uji Statistik menggunakan uji Chi-Square ( $\rho$ value $=0.011$ $<0.05$ ). Cakupan kunjungan dalam memeriksakan kehamilan di Puskesmas Wolio didapatkan data bahwa ibu hamil mengatakan jarak puskesmas memiliki pengaruh tentang cakupan pemeriksaan pada kehamilan yang berada di wilayah kerja Puskesmas Wolio.

Hasil ini menunjukkan bahwa, ibu yang jaraknya mudah ke puskesmas, cakupan untuk memeriksakan kehamilannya yang lengkap adalah 57 orang ibu, dimana akses yang terjangkau merupakan akses yang dapat mudah digunakan oleh ibu dan transportasi lancar sehingga ibu dapat teratur dalam melakukan pemeriksaan kehamilan, sedangkan ibu yang jaraknya mudah tetapi cakupan pemeriksaan kehamilannya tidak lengkap sebanyak 48 responden hal ini dikarenakan ibu yang mempunyai rasa malas untuk memeriksakan 
kehamilannya dan juga ibu yang memiliki pekerjaan yang tidak bisa ditinggalkan sehingga ibu harus menunda untuk pergi memeriksakan kehamilannya di puskesmas.

Adapun ibu yang menyatakan jarak rumah ke pelayanan kesehatan sulit tetapi cakupan pemeriksaan kehamilannya lengkap sebanyak 3 orang hal ini dikarenakan ibu mempunyai pengetahuan dan sikap yang baik tentang pemeriksaan kehamilan, sehingga hal itulah yang menjadi alasan ibu untuk tetap melakukan kunjungan pemeriksaan kehamilan sesuai jadwal yang diberitahukan oleh bidan, sedangkan ibu yang menyatakan jarak sulit dengan cakupan pemeriksaan kehamilannya yang tidak lengkap sebanyak 14 orang, hal ini disebabkan oleh keadaan ibu yang memiliki jarak rumah ke puskesmas lebih dari 15 menit serta tidak memiliki kendaraan pribadi dan keterbatasan biaya sehingga ibu tidak mau memeriksakan kehamilannya secara teratur dipuskesmas sesuai wilayah tempat tinggalnya. Kemudian ada juga ibu yang telah memeriksakan kehamilannya dibeberapa pelayanan kesehatan lainnya, sehingga jumlah kunjungan pemeriksaan kehamilan ibu tersebut di puskesmas tidak dapat tercatat secara lengkap.

Hasil penelitian ini sejalan dengan hasil penelitian yang dilakukan oleh Tarigan yang mendapatkan hasil bahwa pengetahuan ibu hamil, sikap ibu hamil, jarak tempat tinggal dengan puskesmas atau layanan kesehatan, dan dukungan dari suami berhubungan dengan kelengkapan kunjungan antenatal care pada ibu hamil (Tarigan, 2017). Hal ini berbeda dengan penelitian yang dilakukan oleh Syahputri (Choirunissa \& Syaputri, 2018) yang menyatakan bahwa jarak rumah ke pelayanan kesehatan tidak berhubungan dengan pemeriksaan K4 pada ibu hamil di Puskesmas Bakung Provinsi Lampung Tahun 2017.

\section{Hubungan Dukungan Keluarga dengan Cakupan Pemeriksaan Kehamilan}

Berdasarkan penelitian ini, hasilnya menyatakan bahwa terdapat hubungan antara dukungan keluarga dengan cakupan pemeriksaan kehamilan di Puskesmas Wolio dengan hasil uji Statistik yang menggunakan uji Chi-Square $(\rho$ value $=0.005<0.05)$. Dalam cakupan pemeriksaan kehamilan di Puskesmas Wolio dalam hal ini adalah ibu hamil menyatakan bahwa dukungan keluarga sangat mempengaruhi cakupan pemeriksaan kehamilan di wilayah kerja Puskesmas Wolio.

Hasil ini menunjukkan bahwa, ibu yang menyatakan bahwa adanya dukungan dari keluarga dengan cakupan pemeriksaan kehamilannya yang lengkap sebanyak 56 orang hal ini dikarenakan oleh keluarga yang memberikan dukungan penuh kepada ibu hamil, dan menggangap pemeriksaan kehamilan adalah hal yang penting, sehingga dengan pemahaman yang demikian, keluarga akan lebih memperhatikan kesehatan ibu dan bayi yang di kandungannya. Keluarga akan memberikan motivasi kepada ibu hamil agar dapat dengan teratur melakukan kunjungan pemeriksaan kehamilan.

Ibu yang mendapatkan dukungan suami dan keluarga yang baik akan memiliki kesempatan untuk melakukan pemeriksaan kehamilan sesuai standar dibanding dengan ibu yang tidak memiliki motivasi dari suami atau keluarga. Sehingga dapat dijelaskan bahwa, dukungan dari suami dan keluarganya dalam hal ini, memegang peranan yang cukup baik dalam perubahan perilaku Sang ibu untuk melakukan kunjungan pemeriksaan pada kehamilan, karena dengan adanya kekhwatiran suami dan keluarganya akan menjadi peluang untuk terjadinya proses persalinan yang baik. Semakin sering ibu melakukan pemeriksaan kondisi kehamilannya maka pihak keluarga akan semakin tenang dalam menghadapi persalinan, karena dengan demikian ibu dan keluarga akan dapat mengetahui kondisi kehamilan ibu baik terkait dengan kesehatan ibu dan juga kesehatan bayinya.

Ibu yang dukungan keluarganya mendukung tetapi cakupan pemeriksaan kehamilannya tidak lengkap sebanyak 45 orang ibu, hal ini disebabkan oleh ibu yang memeriksakan kehamilannya hanya berkunjung pada saat usia kehamilannya satu bulan, dan pemeriksaan kehamilan selanjutnya, ibu melakukan kunjungan kembali ketika ibu sudah berada di trimester ketiga atau usia yang sudah menghampiri waktu bersalin. Ada juga karakteristik ibu yang jarang atau bahkan tidak mau memeriksakan kehamilannya sehingga pemeriksakan kehamilannya tidak tercatatat lengkap.

Data selanjutnya, yaitu ibu dengan dukungan keluarga yang tidak mendukung ibu untuk memeriksakan kehamilannya tetapi cakupan pemeriksaan kehamilan yang lengkap 
sebanyak 4 responden, hal ini baik, karena adanya kemauan serta kesadaraan ibu yang tinggi akan pentingnya melakukan pemeriksaan kehamilan secara rutin.

Sebagian ibu juga mendapatkan dukungan keluarga yang tidak mendukung ibu untuk memeriksakan kehamilannya dalam cakupan pemeriksaan yang tidak lengkap yaitu 17 orang, karena ibu tidak mempunyai pengetahuan yang bagus dan sikap yang kurang baik dan juga ditambah dengan ibu yang tidak memiliki motivasi lain dari keluarga dan suami. Ibu tidak melakukan pemeriksaan kehamilan secara teratur serta sebagian keluarganya masih mempercayai adanya dukun beranak, sehingga keluarga dari ibu tersebut tidak mendukung untuk melakukan pemeriksaan ke puskesmas. Sebagian juga ibu paritas dengan kelahiran anak pertama sehingga keluarga/suami percaya akan budaya pamali jika keluar rumah diawal kehamilan, yang berdasarkan pernyataan tersebut akan membahayakan kehamilannya. Sebagian dari ibu trauma dengan kehamilan sebelumnya yang pernah mengalami keguguran sehingga timbul rasa takut dan itulah yang faktor yang menjadi penghambat ibu untuk pergi memeriksakan kehamilannya di puskesmas atau pusat kesehatan lainnya.

Hasil penelitian ini sejalan dengan penelitian yang telah dilakukan oleh (Kurniasari

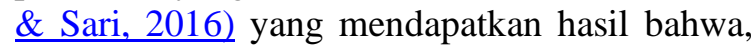
pengetahuan dan dukungan keluarga merupakan beberapa faktor yang paling dominan dalam mempengaruhi kunjungan kehamilan ibu atau kunjungan antenatal care. Hal ini juga didukung oleh pernyataan (Tarigan, 2017) yang menyatakan bahwa suami yang tidak mendukung isterinya dalam melakukan kontrol atau pemeriksaan kehamilan akan memiliki peluang risiko 7,9 kali lebih besar untuk ibu hamil agar tidak melakukan kunjungan antenatal care yang lengkap. Sehingga berdasarkan hal tersebut suami dan keluarga harus ikut terlibat dalam memotivasi ibu hamil agar memeriksakan kehamilannya di puskesmas atau pelayanan kesehatan lainnya.

Hasil ini didukung juga oleh penelitian yang dilakukan oleh Rauf (Rauf \& Amir, 2013), yang menyatakan bahwa terdapat hubungan antara dukungan keluarga dengan pemanfaatan pelayanan ANC. Hasil penelitian lain juga yang dilakukan oleh (Nabilah, 2017), yang mendapatkan hasil bahwa dukungan suami dan juga keluarga memilki pengaruh kepada ibu dalam pelaksanaan antenatal care. Sesuai dengan teori bahwa motivasi adalah sesuatu hal yang dapat mendorong dan merubah perilaku seseorang dalam melakukan sesuatu. Hal tersebut dapat mengacu pada usaha untuk mendapatkan kebutuhan atau suatu tujuan yang diinginkan (Notoatmodjo, 2010).

Adanya dukungan keluarga dapat memberikan kenyamanan baik fisik maupun psikologis bagi ibu hamil, karena ia merasa ingin selalu diperhatikan oleh orang-orang di sekitarnya. Dukungan yang berupa penjelasan, informasi, emosional, harga diri, dan kelompok sosial sangat diperlukan oleh ibu hamil agar dapat terus termotivasi melakukan yang terbaik untuk dirinya dan kandungannya. Hal ini dikarenakan ibu hamil juga merupakan makhluk sosial, memerlukan keberadaan orang lain untuk memberikan dukungan, bantuan, perhatian, dan kerja sama dalam hal menjaga kesehatannya di saat masa kehamilannya (Indriyani \& Asmuji, 2014).

\section{KESIMPULAN DAN SARAN}

Berdasarkan hasil penelitian yang dilakukan maka dapat ditarik kesimpulan bahwa ada hubungan antara kualitas pemeriksaan kehamilan, jarak ke pelayanan kesehatan dan dukungan keluarga di wilayah kerja Puskesmas Wolio Kota Baubau.

Saran yang dapat diberikan dari hasil penelitian ini yaitu disarankan kepada tenaga kesehatan agar selalu memberikan informasi kepada ibu hamil dan keluarga yang mendampingi, tentang pentingnya melakukan kunjungan antenatal care secara lengkap sehingga ibu dan keluarganya dapat mengetahui kondisi ibu dan janin. Diharapkan juga agar tenaga kesehatan terutama bidan untuk selalu membantu memantau perkembangan ibu hamil sampai masa persalinan tiba.

\section{DAFTAR PUSTAKA}

Choirunissa, R., \& Syaputri, N. D. (2018). Analisis Faktor yang Berhubungan dengan Pemeriksaan K4 Pada Ibu Hamil Di Puskesmas Bakung Provinsi Lampung Tahun 2017. 4, 22.

Indriyani, D., \& Asmuji. (2014). Keperawatan Maternitas. Ar-Ruzz Media.

Kemenkes. (2014). Profil Kesehatan Indonesia Tahun 2014. Kementerian Kesehatan Republik Indonesia. https://www. kemkes.go.id/resources/download/pusdat 
in/profil-kesehatan-indonesia/Indonesia\% 20Health\%20Profile\%202014.pdf

Kemenkes. (2015). Profil Kesehatan Indonesia Tahun 2015. Kementerian Kesehatan Republik Indonesia. https://www. kemkes. go.id/resources/ download/ pusdatin/profil- kesehatan -indonesia/ indonesian\%20health\%20profile\%20201 5.pdf

Kemenkes. (2016). Profil Kesehatan Indonesia Tahun 2016. Kementerian Kesehatan Republik Indonesia. https://www. kemkes.go.id/resources/download/pusdat in/profil-kesehatan- indonesia/ProfilKesehatan-Indonesia-2016.pdf

Kurniasari, D., \& Sari, V. Y. (2016). FaktorFaktor yang Mempengaruhi Kunjungan Kehamilan Di Puskesmas Kesumadadi Kabupaten Lampung Tengah Tahun 2016. 2, 11.

Nabilah, F. (2017). Hubungan Dukungan Suami Dengan Keteraturan Antenatal Care (ANC) Pada Ibu Hamil Trisemester III
Di BPM Istri Suami Sleman, Yogyakarta. http://digilib.unisayogya.ac.id/2707/1/Na skah\%20Publikasi\%20Fasya\%20Nabilah $\% 20 \% 281610104431 \% 29$.pdf

Notoatmodjo, S. (2010). Metode Penelitian Kesehatan. Rineka Cipta.

Puskesmas Wolio. (2017). Laporan Profil Kesehatan Puskesmas Wolio. Pusat Kesehatan Masyarakat Wolio.

Rachmawati, A. I., Puspitasari, R. D., \& Cania, E. (2017). Faktor-faktor yang Memengaruhi Kunjungan Antenatal Care (ANC) Ibu Hamil. 5.

Rauf, N. I., \& Amir, M. Y. (2013). Faktor yang Berhubungan Dengan Pemanfaatan Pelayanan Antenatal Care Di Puskesmas Minasa Upa Kota Makassar Tahun 2013. 11.

Tarigan, D. F. P. (2017). Faktor Kelengkapan Kunjungan Antenatal Care Di Puskesmas Sei Kepayang Kabupaten Asahan Tahun 2017. 2(2), 17. 